\title{
REVIEW
}

\section{Evidence of incompatibility for topical anionic agents used in conjunc- tion with chlorhexidine gluconate: A systematic review}

\author{
Gary Tran', Thy N Huynh, Finola M Bruins ${ }^{1}$, Najeah Ahmad², William A Budris ${ }^{2}$, \\ Alba Posligua ${ }^{1}$, Josh A Hammel ${ }^{1}$, Beatrice Nardone ${ }^{1}$, Dennis P West ${ }^{1 *}$ \\ ${ }^{1}$ Department of Dermatology, Feinberg School of Medicine, Northwestern University, Chicago, Illinois, United States of America \\ ${ }^{2}$ Department of Pharmacy, Northwestern Medicine, Northwestern Memorial Hospital, Chicago, Illinois, United States of America
}

\begin{abstract}
Chlorhexidine gluconate (CHG) is a widely used antiseptic agent for skin and wound disinfection. The cationic properties of CHG may allow its inactivation and precipitation by anionic agents in commonly used topical agents. We conducted a systematic review by searching through PubMed, Cochrane Library, and Web of Science databases and selected original research articles reporting on CHG incompatibility, defined as inactivation or precipitation. The search yielded 22 publications that demonstrated CHG incompatibility via: (1) reduced antibacterial activity (carbomer, acrylates/C10-C30 alkyl acrylate crosspolymer, dentin, bovine serum albumin, copolymer M239144, sodium lauryl sulfate, heat-killed microbes, triethanolamine, and bark cork); and (2) visible precipitate formation (sodium hypochlorite, EDTA, saline, ethanol, andnystatin). Only three publications reported on CHG incompatibility in dermatology, specifically for carbomer, triethanolamine, and acrylates/C10-C30 alkyl acrylate crosspolymer. Although limited evidence linking CHG incompatibility and anionic agents exists, clinicians should carefully consider the nature of topical agents used if CHG is concurrently applied. Increased awareness of CHG incompatibility may result in better antibacterial activity thus ensuring optimal patient management.
\end{abstract}

Keywords: chlorhexidine; incompatibility; inactivation; skin; reduced antibacterial activity; precipitation; systematic review

Citation: Tran G, Huynh TN, Bruins FM, Ahmad N, Budris WA, et al. Evidence of incompatibility for topical anionic agents used in conjunction with chlorhexidine gluconate: A systematic review. J Surg Dermatol 2021; 6(1): 21; http:// dx.doi.org/10.18282/jsd.v6.i1.21.

*Correspondence to: Dennis P. West, Department of Dermatology, Feinberg School of Medicine, Northwestern University, 676 N. St. Clair Street, Suite 1600, Chicago, IL 60611, USA; dwest@ northwestern.edu

Received: $5^{\text {th }}$ July 2020; Accepted: $22^{\text {nd }}$ September 2020; Published Online: $4^{\text {th }}$ October 2020

\section{Introduction}

Chlorhexidine gluconate (CHG) is a widely used, broad-spectrum antiseptic agent for skin and wound disinfection ${ }^{[1]}$. The cationic bisbiguanide moiety is a characteristic feature of $\mathrm{CHG}$ that allows its binding to keratinocytes. This produces bacteriostatic and bactericidal effects from the interactions with anionic bacterial cell walls ${ }^{[2,3]}$. CHG has been shown to have cumulative antibacterial persistence on the $\operatorname{skin}^{[4]}$. Despite all these positive attributes, its cationic properties may allow inactivation or precipitation by anionic agents found in products commonly applied as emollients immediately after $\mathrm{CHG}$ application. We conducted a systematic review to evaluate the evidence of $\mathrm{CHG}$ incompatibility in a dermatological clinical setting.

Copyright (C) 2021 Tran G, et al. This is an Open Access article distributed under the terms of the Creative Commons Attribution-Non Commercial 4.0 International License (http://creativecommons.org/licenses/by-nc/4.0/), permitting all non-commercial use, distribution, and reproduction in any medium, provided the original work is properly cited. 


\section{Materials and methods}

This study was performed according to the Preferred Reporting Items for Systematic Reviews and MetaAnalyses (PRISMA) statement, where applicable (the PRISMA checklist can be found in Appendix 1$)^{[5]}$. We searched PubMed, Cochrane Library, and Web of Science databases from their inception up to October 2015 using the following key words: "chlorhexidine AND inactivation", "chlorhexidine AND incompatibility", "chlorhexidine AND precipitate", and "chlorhexidine AND anionic". Results were filtered for English language and human studies, if possible, within the databases. Original research articles were deemed eligible if there are reported chlorhexidine incompatibilities (i.e., reduced antibacterial activity by inactivation or by visible physical precipitation). Two independent reviewers (Tran G and Huynh TN) selected, screened, and reviewed the search results. Variance was reconciled by consensus or, if necessary, through a third reviewer (West DP). Data collection included the type of study (in vivo or ex vivo), incompatible agents, and significance of incompatibility reported as $p$ values (Table 1).

\section{Results}

The search yielded 414 articles: 78 from PubMed, 15 from Cochrane Library, and 321 from Web of Science. 231 articles were found evaluable after removal of duplicates. After screening the titles and/or abstracts, we excluded 209 articles and hence 22 eligible articles remained. After the final screening, only three articles addressed the dermatologic usage of topical CHG and its incompatibility, specifically addressing the following compounds: carbomer $^{[6]}$, triethanolamine ${ }^{[7,8]}$, and acrylates/C10-C30 alkyl acrylate crosspolymer ${ }^{[6,7]}$. Figure 1 showed a flow diagram outlining the selection of articles. Of the 22 eligible articles, 10 articles reported reduced antibacterial activity from the following compounds: carbomer ${ }^{[6]}$, acrylates/C10-C30 alkyl acrylate crosspolymer $^{[6,7]}$, dentin ${ }^{[9-12]}$, bovine serum albumin ${ }^{[11]}$, copolymer M239144 ${ }^{[13]}$, sodium lauryl sulfate ${ }^{[14]}$, heat-killed microbes ${ }^{[9,12]}$, triethanolamine $e^{[7,8]}$, and bark cork $^{[15]}$. The 12 remaining articles reported precipitation related to the following compounds: sodium hypochlorite ${ }^{[16-25]}$, EDTA $^{[16-18,26]}$, saline ${ }^{[16]}$, ethanol ${ }^{[16]}$, and nystatin ${ }^{[27]}$. The most commonly reported incompatibility was sodium hypochlorite (bleach, $N=10,45 \%$ ) and the most commonly reported indication for CHG and its incompatibility was oral mucosal applications $(N=19,86 \%)$.
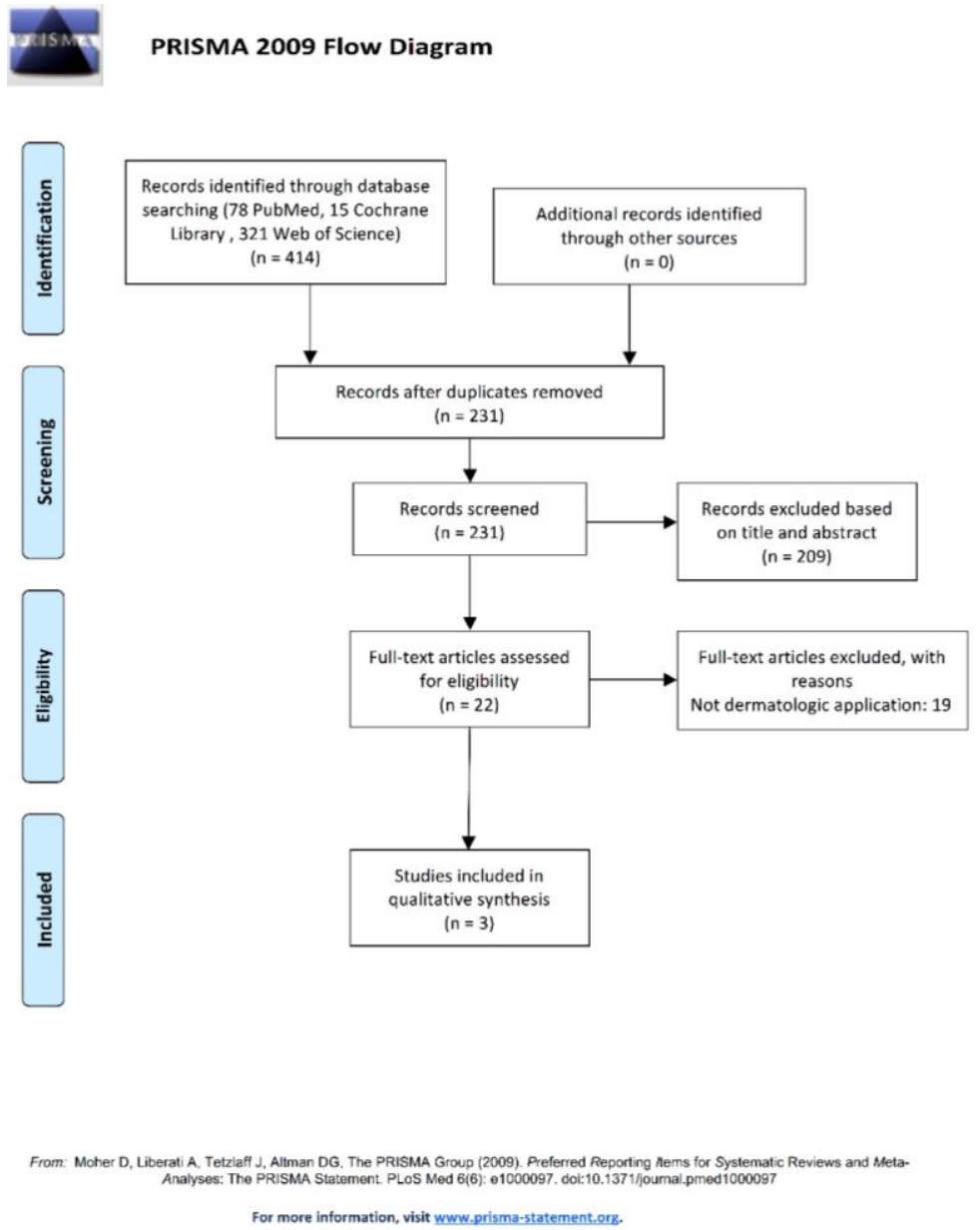

Figure 1. The PRISMA flow diagram for study selection

\section{Discussion}

A clinically advantageous feature of CHG compared to other antibacterial agents is its affinity to keratinocytes and persistence within skin tissue. To maintain this clinical feature, it is important to be aware that some concurrently applied topical products may have the potential to disrupt the persistent antibacterial activity. This systematic review identified three publications reporting CHG inactivation after concurrent application of topical agents ${ }^{[6-8]}$. Emulsifiers and thickeners found in these topical agents contributed to $\mathrm{CHG}$ inactivation. As revealed by our systematic review, there was a distinct lack of literature addressing topical CHG incompatibility.

In an ex vivo study by Benson et al., anionic surfactant systems almost completely eliminated prolonged residual antibacterial effect of $\mathrm{CHG}$, whereas minimal effect occurred with nonionic products over the same prolonged residual period ${ }^{[7]}$. 
Table 1. Summary of articles exploring dermatologic chlorhexidine incompatibility

\begin{tabular}{|c|c|c|c|c|}
\hline Study & Type of study & Bacteria & Inactivating agent & $p$ value \\
\hline Kaiser et al. $(2009)^{[6]}$ & in vivo + ex vivo & $\begin{array}{l}\text { Serratia marcescens, in vivo } \\
\text { Staphylococcus aureus, ex vivo }\end{array}$ & $\begin{array}{l}\text { Carbomer, C10-C30 alkyl } \\
\text { acrylate crosspolymer }\end{array}$ & $<0.0001$ \\
\hline Benson et al. $(1990)^{[7]}$ & ex vivo & Serratia marcescens & $\begin{array}{l}\text { Triethanolamine, C10-C } 30 \text { alkyl acrylate cross- } \\
\text { polymer (Vaseline }{ }^{\circledR} \text { Intensive Care) }\end{array}$ & $<0.01$ \\
\hline Walsh et al. $(1987)^{[8]}$ & in vivo & Escherichia coli & Triethanolamine & $<0.001$ \\
\hline
\end{tabular}

Triethanolamine and C10-C30 alkyl acrylate crosspolymer were the implicated inactivating agents in the anionic surfactant system. Another ex vivo study also demonstrated statistically significant decreases in $\log _{10}$ reductions in alcohol hand sanitizing gels ${ }^{[6]}$. Of note, emulsifying and thickening agents, carbomer, and C10-C30 alkyl acrylate crosspolymer were associated with CHG inactivation rather than the alcohol itself. Moreover, these results paralleled in vivo testing involving 11 human subjects. Hand creams containing triethanolamine, an emulsifier and thickener, yielded similar in vivo CHG inactivation ${ }^{[8]}$. Based on the Cosmetic Ingredient Review (CIR) Expert Panel, triethanolamine, carbomer, and C10-C30 alkyl acrylate crosspolymer were found in 3756, 1610 and 1696 cosmetic formulations, respectively ${ }^{[28-30]}$. This demonstrated the prevalence of these compounds as well as the potential for inactivation if concurrently applied.

CHG is widely known for its antibacterial superiority over many antiseptics and its substantial residual activity on $\operatorname{skin}^{[31-34]}$. CHG typically has a very rapid action onset with high bacterial kill rate efficacy and additionally has been shown to reduce bacterial counts of drug-resistant Acinetobacter baumannii and methicillin-resistant Staphylococcus aureus strains by $99.9 \%$ within three minutes ${ }^{[35,36]}$. After several decades of clinical use with no clinically significant events reported concerning the interaction and/or inhibition of antibacterial effect with concurrent application of other topical products, the immediate kill by CHG might be its most important clinical property. One study suggested that the residual kill of CHG may be an artifact of testing protocols and was dependent on the skin being wet ${ }^{[37]}$. Generally, if avoidance of an incompatible agent is not possible, and because of the rapid and relatively complete kill rate by CHG, topical anionic agents may likely be applicable after a short period, with a low likelihood of impaired CHG efficacy. Despite this, clinicians should weigh the risks and benefits in deciding the appropriate amount of elapsed time subsequent to $\mathrm{CHG}$ application to ensure adequate efficacy.

A limitation of this study was that chemistry (non-biomedical) databases were not included - such databases may yield additional supporting evidence in re- gards to the incompatibility of anionic agents that may be utilized in biomedical products applied to skin or mucous membranes concurrent to $\mathrm{CHG}$ use. Despite the fact that we only reported three agents for CHG inactivation with concurrent application, there are other agents not yet investigated and reported for this potential interaction. Moreover, there is a clear gap in clinician knowledge of CHG incompatibility. According to a survey in Washington State, a cohort of only $48 \%$ health personnel was aware of CHG inactivation by some topical anionic moisturizers ${ }^{[38]}$. This survey illustrated a need for further education and research on CHG incompatibility with selected concurrently used topical agents. Future exploration of this issue should perhaps focus on health outcomes to delineate the clinical significance of $\mathrm{CHG}$ incompatibility.

\section{Conclusion}

Despite widespread use of anionic agents in topically applied products, this systematic review of CHG incompatibility, as measured by reduced antibacterial activity or physical precipitation, yielded very limited evidence of incompatibility and only with very few anionic agents. Given the several decades of clinical use without reports of reduced efficacy due to topical incompatibility, CHG's relatively immediate killing property may be its predominant function and therefore the potential for reduction in antibacterial efficacy may be minimal due to this ability. However, in light of the very limited but relatively high level of evidence for ex vivo incompatibility, clinicians should carefully consider the possibility of CHG incompatibility with concurrent use of topical anionic agents. Clinicians should be aware of the ingredients in topical emollient/skin regimens for patients who concurrently use CHG. Although further investigation to determine the ionic nature of topical agents may be somewhat tedious, this information affords the opportunity for optimizing antibacterial activity and, ultimately, health outcomes.

\section{Author contributions}

The study was conceived and designed by Ahmad N, Budris WA, Posligua A, Hammel JA, Nardone B, and 
West DP. Tran G, Huynh TN, and West DP reviewed the articles. The manuscript was prepared by Tran G, Huynh TN, and Bruins FM with revisions by Tran G, Huynh TN, Bruins FM, Ahmad N, Budris WA, Posligua A, Hammel JA, Nardone B, and West DP.

\section{Conflict of interest}

West DP is a consultant for Sage Products LLC but he did not receive any financial support to conduct the work reflected in this research. All the other authors declare no potential conflict of interest with respect to the research, authorship, and/or publication of this article.

\section{Supplementary information}

Appendix 1: The PRISMA checklist of items to include when reporting a systematic review or meta-analysis. The supplementary information is available free of charge on JSD's website at doi: 10.18282/jsd.v1.i2.21.

\section{References}

1. McDonnell G, Russell AD. Antiseptics and disinfectants: Activity, action, and resistance. Clin Microbiol Rev 1999; 12(1): 147-79.

2. Abdallah C. Perioperative chlorhexidine allergy: Is it serious? J Anaesthesiol Clin Pharmacol 2015; 31(2): 152154. doi: 10.4103/0970-9185.155140.

3. Jones CG. Chlorhexidine: Is it still the gold standard? Periodontol 2000 1997; 15(1): 55-62. doi: 10.1111/j.1600-0757.1997.tb00105.x.

4. Aly R, Maibach HI. Comparative study on the antimicrobial effect of $0.5 \%$ chlorhexidine gluconate and $70 \%$ isopropyl alcohol on the normal flora of hands. Appl Environ Microbiol 1979; 37(3): 610-613.

5. Moher D, Liberati A, Tetzlaff J, Altman DG, PRISMA group. Preferred reporting items for systematic reviews and meta-analyses: The PRISMA statement. Ann Intern Med 2009; 151(4): 264-269. doi: 10.7326/0003-4819-151-4-200908180-00135.

6. Kaiser N, Klein D, Karanja P, Greten Z, Newman J. Inactivation of chlorhexidine gluconate on skin by incompatible alcohol hand sanitizing gels. Am J Infect Control 2009; 37(7): 569-573. doi: 10.1016/j.ajic.2008.12.008.

7. Benson L, LeBlanc D, Bush L, White J. The effects of surfactant systems and moisturizing products on the residual activity of a chlorhexidine gluconate hand wash using a pigskin substrate. Infect Control Hosp Epidemiol 1990; 11(2): 67-70. doi: 10.2307/30144264.

8. Walsh B, Blakemore PH, Drabu YJ. The effect of hand cream on the antibacterial activity of chlor- hexidine gluconate. J Hosp Infect 1987; 9(1): 30-33. doi: 10.1016/0195-6701(87)90091-0.

9. Portenier I, Haapasalo H, Ørstavik D, Yamauchi M, Haapasalo M. Inactivation of the antibacterial activity of iodine potassium iodide and chlorhexidine digluconate against Enterococcus faecalis by dentin, dentin matrix, type-I collagen, and heat-killed microbial whole cells. J Endod 2002; 28(9): 634-637. doi: 10.1097/00004770-200209000-00002.

10. Haapasalo HK, Sirén EK, Waltimo TMT, Ørstavik D, Haapasalo MPP. Inactivation of local root canal medicaments by dentine: An in vitro study. Int Endod J 2000; 33(2): 126-131. doi: 10.1046/j.1365-2591.2000.00291.x.

11. Portenier I, Haapasalo H, Rye A, Waltimo T, Ørstavik D, et al. Inactivation of root canal medicaments by dentine, hydroxylapatite and bovine serum albumin. Int Endod J 2001; 34(3): 184-188. doi: 10.1046/j.1365-2591.2001.00366.x.

12. Mohammadi Z, Shalavi S. The effect of heat-killed Candida albicans and dentin powder on the antibacterial activity of chlorhexidine solution. Iran Endod J 2012; 7(2): 63-67.

13. Claydon N, Addy M, Ridge D, Jackson R. An evaluation of an antiadhesive copolymer agent on plaque inhibition by chlorhexidine. J Clin Periodontol 1996; 23(10): 952-954. doi: 10.1111/j.1600-051X.1996.tb00517.x.

14. Barkvoll P, Rølla G, Svendsen K. Interaction between chlorhexidine digluconate and sodium lauryl sulfate in vivo. J Clin Periodontol 1989; 16(9): 593-595. doi: 10.1111/j.1600-051X.1989.tb02143.x.

15. Linton $\mathrm{KB}$, George $\mathrm{E}$. Inactivation of chlorhexidine ("hibitane") by bark corks. Lancet 1966; 1(7451): 1353-1355. doi: 10.1016/S0140-6736(66)92141-6.

16. Prado M, Santos Júnior HMS, Rezende CM, Pinto AC, Faria RB, et al. Interactions between irrigants commonly used in endodontic practice: A chemical analysis. J Endod 2013; 39(4): 505-510. doi: 10.1016/j.joen.2012.11.050.

17. Rossi-Fedele G, Doğramaci EJ, Guastalli AR, Steier L, de Figueiredo JAP. Antagonistic interactions between sodium hypochlorite, chlorhexidine, EDTA, and citric acid. J Endod 2012; 38(4): 426-431. doi: 10.1016/j.joen.2012.01.006

18. Shenoy A, Bolla N, Sayish, Sarath RK, Ram CHS, et al. Assessment of precipitate formation on interaction of irrigants used in different combinations: An in vitro study. Indian J Dent Res 2013; 24(4): 451-455. doi: 10.4103/0970-9290.118392.

19. Gasic J, Popovic J, Živković S, Petrovic A, Barac R, et al. Ultrastructural analysis of the root canal walls after simultaneous irrigation of different sodium hypochlorite concentration and $0.2 \%$ chlorhexidine glu- 
conate. Microsc Res Tech 2012; 75(8): 1099-1103. doi: 10.1002/jemt.22036.

20. Krishnamurthy S, Sudhakaran S. Evaluation and prevention of the precipitate formed on interaction between sodium hypochlorite and chlorhexidine. J Endod 2010; 36(7): 1154-1157. doi: 10.1016/j.joen.2010.01.012.

21. Akisue E, Tomita VS, Gavini G, de Figueiredo JAP. Effect of the combination of sodium hypochlorite and chlorhexidine on dentinal permeability and scanning electron microscopy precipitate observation. J Endod 2010; 36(5): 847-850. doi: 10.1016/j.joen.2009.11.019.

22. Bui TB, Baumgartner JC, Mitchell JC. Evaluation of the interaction between sodium hypochlorite and chlorhexidine gluconate and its effect on root dentin. J Endod 2008; 34(2): 181-185. doi: 10.1016/j.joen.2007.11.006.

23. Cintra LTA, Watanabe S, Samuel RO, da Silva Facundo AC, de Azevedo Queiroz ÍO, et al. The use of $\mathrm{NaOCl}$ in combination with $\mathrm{CHX}$ produces cytotoxic product. Clin Oral Investig 2014; 18(3): 935-940. doi: 10.1007/s00784-013-1049-5.

24. Nowicki JB, Sem DS. An in vitro spectroscopic analysis to determine the chemical composition of the precipitate formed by mixing sodium hypochlorite and chlorhexidine. J Endod 2011; 37(7): 983-988. doi: 10.1016/j.joen.2011.03.033.

25. Basrani BR, Manek S, Sodhi RNS, Fillery E, Manzur A. Interaction between sodium hypochlorite and chlorhexidinegluconate. J Endod 2007; 33(8): 966-969. doi: 10.1016/j.joen.2007.04.001.

26. Rasimick BJ, Nekich M, Hladek MM, Musikant BL, Deutsch AS. Interaction between chlorhexidine digluconate and EDTA. J Endod 2008; 34(12): 1521-1523. doi: 10.1016/j.joen.2008.08.039.

27. Barkvoll P, Attramadal A. Effect of nystatin and chlorhexidine digluconate on Candida albicans. Oral Surg Oral Med Oral Pathol 1989; 67(3): 279-281. doi: 10.1016/0030-4220(89)90354-X.

28. Fiume MM, Heldreth B, Bergfeld WF, Belsito DV, Hill RA, et al. Safety assessment of triethanolamine and triethanolamine-containing ingredients as used in cosmetics. Int J Toxicol 2013; 32(3 Suppl): 59S-83S. doi: $10.1177 / 1091581813488804$

29. Cosmetic Ingredient Review Expert Panel. Annual review of cosmetic ingredient safety assessments - 2001/2002.
Int J Toxicol 2003; 22(Suppl 1): 1-35.

30. Cosmetic Ingredient Review [Internet]. Final Safety Assessment: Crosslinked alkyl acrylates as used in cosmetics. [cited 2015 December 15]. Available from: http://online.personalcarecouncil.org/ctfa-static/online/list s/cir-pdfs/FR583.pdf.

31. Maki DG, Ringer M, Alvarado CJ, Ringer M. Prospective randomised trial of povidone-iodine, alcohol, and chlorhexidine for prevention of infection associated with central venous and arterial catheters. Lancet 1991; 338(8763): 339-343. doi: 10.1016/0140-6736(91)90479-9.

32. Darouiche RO, Wall MJ Jr, Itani KMF, Otterson MF, Webb AL, et al. Chlorhexidine-alcohol versus povidoneiodine for surgical-site antisepsis. N Engl J Med 2010; 362(1): 18-26. doi: 10.1056/NEJMoa0810988.

33. Macias JH, Arreguin V, Munoz JM, Alvarez JA, Mosqueda JL, et al. Chlorhexidine is a better antiseptic than povidone iodine and sodium hypochlorite because of its substantive effect. Am J Infect Control 2013; 41(7): 634- 637. doi: 10.1016/j.ajic.2012.10.002.

34. Popovich KJ, Lyles R, Hayes R, Hota B, Trick W, et al. Relationship between chlorhexidine gluconate skin concentration and microbial density on the skin of critically ill patients bathed daily with chlorhexidine gluconate. Infect Control Hosp Epidemiol 2012; 33(9): 889-896. doi: $10.1086 / 667371$.

35. Adams D, Quayum M, Worthington T, Lambert P, Elliott T. Evaluation of a $2 \%$ chlorhexidine gluconate in $70 \%$ isopropyl alcohol skin disinfectant. J Hosp Infect 2005; 61(4): 287-290. doi: 10.1016/j.jhin.2005.05.015.

36. DeBaun B. Evaluation of the antimicrobial properties of an alcohol-free $2 \%$ chlorhexidine gluconate solution. AORN J 2008; 87(5): 925-933. doi: 10.1016/j.aorn.2008.02.001.

37. Rutter JD, Angiulo K, Macinga DR. Measuring residual activity of topical antimicrobials: Is the residual activity of chlorhexidine an artefact of laboratory methods? J Hosp Infect 2014; 88(2): 113-115. doi: 10.1016/j.jhin.2014.06.010.

38. Marino C, Cohen M. Washington State hospital survey 2000: Gloves, handwashing agents, and moisturizers. Am J Infect Control 2001; 29(6): 422-424. doi: 10.1067/mic.2001.117298. 